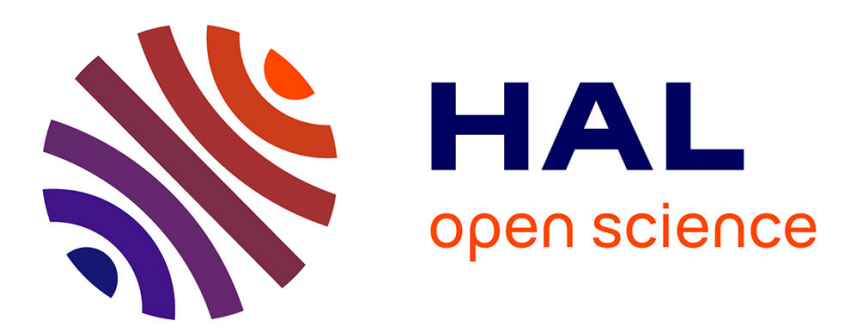

\title{
Self-diffusion coefficients of TBBA : comparison between neutron and NMR results
}

\author{
F. Volino, A.J. Dianoux, A. Heidemann
}

\section{To cite this version:}

F. Volino, A.J. Dianoux, A. Heidemann. Self-diffusion coefficients of TBBA: comparison between neutron and NMR results. Journal de Physique Lettres, 1979, 40 (22), pp.583-586. 10.1051/jphyslet:019790040022058300 . jpa-00231693

\section{HAL Id: jpa-00231693 https://hal.science/jpa-00231693}

Submitted on 1 Jan 1979

HAL is a multi-disciplinary open access archive for the deposit and dissemination of scientific research documents, whether they are published or not. The documents may come from teaching and research institutions in France or abroad, or from public or private research centers.
L'archive ouverte pluridisciplinaire HAL, est destinée au dépôt et à la diffusion de documents scientifiques de niveau recherche, publiés ou non, émanant des établissements d'enseignement et de recherche français ou étrangers, des laboratoires publics ou privés. 


\title{
Self-diffusion coefficients of TBBA : comparison between neutron and NMR results
}

\author{
F. Volino,
}

Equipe de Physico-Chimie Moléculaire, Section de Physique du Solide, Département de Recherche Fondamentale, Centre d'Etudes Nucléaires de Grenoble, 85X, 38041 Grenoble Cedex, France

\author{
A. J. Dianoux and A. Heidemann \\ Institut Laue-Langevin, 156X, 38042 Grenoble Cedex, France
}

(Reçu le 24 août 1979, accepté le 25 septembre 1979)

\begin{abstract}
Résumé. - On a mesuré les coefficients d'auto-diffusion moyens par diffusion quasi-élastique de neutrons en utilisant la technique de rétrodiffusion, dans les phases smectique A, nématique et isotrope de TBBA. Ces résultats sont comparés à des résultats antérieurs obtenus par neutrons et RMN. On trouve que l'accord n'est bon que pour les phases smectique $A$ et isotrope. On en déduit que les résultats $R M N$ pour la phase nématique sont probablement incorrects. On présente également un modèle simple pour l'auto-diffusion dans les phases smectique A et nématique qui est en bon accord avec nos résultats.
\end{abstract}

\begin{abstract}
The average self-diffusion coefficients have been measured by neutron quasi-elastic scattering using the back-scattering technique, in the smectic A, nematic and isotropic phases of TBBA. The results are compared with previous neutron and NMR results. We find that the agreement is good for the smectic $A$ and isotropic phases only. We deduce that the NMR results are probably incorrect for the nematic phase. A simple model for selfdiffusion in the smectic $A$ and nematic phases which satisfactorily fits our results is also presented.
\end{abstract}

1. Introduction. - The knowledge of the selfdiffusion coefficients in liquid crystals is important for the understanding of the flow properties of these systems. High resolution neutron spectroscopy using the back-scattering technique is now a suitable method for measuring self-diffusion coefficients. In previous papers [1, 2] we have presented such measurements for the smectic $\mathrm{C}$ and smectic $\mathrm{A}$ phases of terephtal-bis-butyl-aniline (TBBA), and found that the results were in good agreement with those of ref. [3] obtained using a NMR spin-echo method. We have now extended these neutron measurements on TBBA to the high temperature smectic A phase, the nematic phase and the isotropic phase. In this paper, we first present the corresponding results. Then we compare them with those obtained by NMR methods in the same phases. Finally, we develop a very simple model for the diffusion in smectic and nematic phases that we fit to the present results. We end the paper by a short discussion on the reliability of the various methods to measure self-diffusion coefficients in liquid crystals.

2. Experimental results. - The measurements were performed with the back-scattering spectrometer IN10 of the I.L.L. The experimental conditions were the same as previously $[1,2]$, except that the scattering angles corresponded to smaller $Q$ values : $0.07,0.11$ and $0.15 \AA^{-1}-Q$ is the neutron momentum transfer -. In that sense, the experimental conditions for the measurement of translational self-diffusion coefficients are improved. Due to the lack of sufficient beam time and also due to difficulty in obtaining good, large monodomains suitable for this experiment, we used only a non-aligned sample. In this way, the data can only give an average selfdiffusion coefficient $\bar{D}$. . The quasi-elastic spectra obtained are similar to those presented in refs. [1,2] and have been analyzed in the same way in terms 
of a single Lorentzian scattering law. In the temperature and $Q$ ranges studied, the full width at half maximum $2 \Delta$ of this Lorentzian was found to be proportional to $Q^{2}$ within experimental accuracy. The self-diffusion coefficient $\bar{D}$ was defined by the relation

$$
2 \Delta=2 \hbar \bar{D} Q^{2}
$$

Eq. (1) was fitted to the data yielding a value of $\bar{D}$. Figure 1 shows examples of plots $2 \Delta$ versus $Q^{2}$ together with the best fitted straight line. Figure 2 shows the corresponding values of $\bar{D}$ versus reciprocal temperature. It is seen that $\bar{D}$ increases with temperature with a small jump at the smectic A-nematic transition. As the nematic-isotropic transition is approached, the curve flattens and a very small negative jump at this transition cannot be excluded.

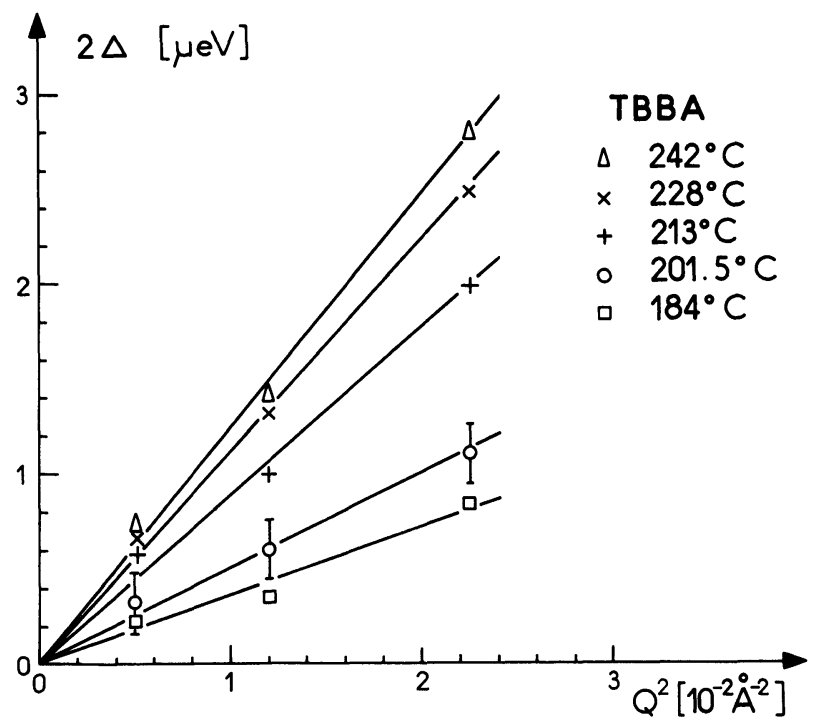

Fig. 1. - Full width at half maximum $2 \Delta$ as a function of $Q^{2}$ of a Lorentzian scattering law convoluted with the instrumental resolution and fitted to the neutron quasi-elastic spectra together with a flat background for various temperatures. The straight lines are the best fits of Eq. (1) to the points.

3. Comparison with NMR data. - 3.1 SMECTIC A PHASE. - In refs. [1] and [2], we have shown that our neutron results were (i) in good agreement with the NMR measurements, presented in ref. [3], made using a two pulse method (the sample being oriented at the magic angle $\left(\sim 55^{\circ}\right)$ with respect to the magnetic field) and (ii) in serious disagreement with other NMR measurements presented in ref. [4] made using a more general multipulse method. The corresponding value of $\bar{D}$ at $184^{\circ} \mathrm{C}$ in the smectic $\mathrm{A}$ phase was indeed found to be about 2.5 times smaller than our value (and that of ref. [3]). Later, an explanation was produced to explain why this multipulse method could have given wrong results and modifications

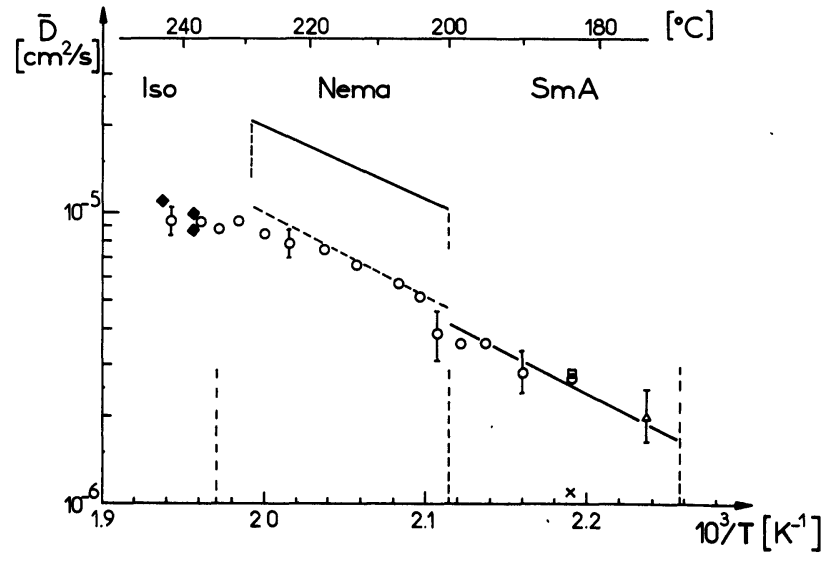

Fig. 2. - Average self-diffusion coefficients of TBBA versus reciprocal temperature in the smectic $A$, nematic and isotropic phases. Open symbols refer to neutron scattering; $O$ : present work, $\square$ from ref. [2], $\Delta$ from ref. [1]. Other symbols : - mean value deduced from the NMR data of ref. [3] in the smectic A phase, and from ref. [6] in the nematic phase ; $\wedge$ :NMR values in the isotropic phase, from ref. [3]; $\times$ : NMR value deduced from ref. [4]. The broken line ---- represents the value of $\bar{D}$ in the nematic phase, predicted by the model described in section 4 . See text for details.

of the multipulse sequences have been proposed [5]. To compare the complete neutron data in the smectic A phase with the results of ref. [3], we have taken the values of $D_{\|}$and $D_{\perp}$ shown in figure 6 of ref. [3] and calculated $\bar{D}$ using the relation :

$$
\bar{D}=\frac{1}{3} D_{\|}+\frac{2}{3} D_{\perp} \text {. }
$$

The result is shown by a full line in figure 2 . The good agreement with the neutron results in the whole smectic A phase is an additional argument for the reliability of both the neutron method and the NMR method of ref. [3] to measure diffusion coefficients in smectic phases.

3.2 Nematic Phase. - Measurements of $D_{\|}$and $D_{\perp}$ in the nematic phase of TBBA using a NMR method different from the two above mentioned methods, have been presented in ref. [6]. This method, which is a particular two pulse method, uses the properties of the so-called nematic echo [7]. To compare these results with the neutron results, we have taken the values of $D_{\|}$and $D_{\perp}$ shown in figure 1 of ref. [6] and calculated $\bar{D}$ as above. The result is also shown in full line in figure 2 and it is seen that now an important disagreement exists, the NMR values being more than twice as large as the neutron values.

3.3 IsOTROPIC PHASE. - Measurements of $D$ in the isotropic phase of TBBA have been performed using the classical NMR method. The results are given in figure 6 of ref. [3] and are reproduced in figure 2. It is seen that, as in the smectic A phase, 
the agreement with the neutron results is again very good.

Since agreement between the neutron and NMR results is good in the smectic A phase - where the NMR method is relatively simple - and in the isotropic phase - where the classical NMR method is known to give reliable results -, we conclude that the NMR results of ref. [6] for the nematic phase are in error. This method yields indeed selfdiffusion coefficients which are too large, although their temperature dependence seems to be correct. We now attempt to explain the neutron results by means of a simple model.

4. A simple model for self-diffusion in nematic and smectic phases. - We assume that in the nematic and smectic $\mathrm{A}$ phases, the diffusion process parallel and perpendicular to the director is thermally activated. We assume moreover that the only difference between the two phases is the existence, in the smectic A phase, and along the director anly of a periodic (sinusoidal) potential of amplitude $V$, which is responsible for the existence of the smectic layers. According to this model, no discontinuity is expected for $D_{\perp}$ and we should have, for both phases

$$
D_{\perp}(T)=A_{\perp} \exp \left[-\frac{E_{\perp}}{k_{\mathrm{B}} T}\right]
$$

where $E_{\perp}$ is the activation energy for diffusion perpendicular to the director and $A_{\perp}$ a scaling factor. For $D_{\|}$, the problem is slightly more complicated. In the nematic phase no extra potential exist and we should clearly have

$$
D_{\|}^{\text {nem }}(T)=A_{\|} \exp \left[-\frac{E_{\|}}{k_{\mathrm{B}} T}\right]
$$

where $E_{\|}$is the activation energy for diffusion parallel to the director and $A_{\|}$another scaling factor. In the smectic A phase, the problem has been solved in ref. [8] and the result is

$$
D_{\|}^{\text {smA }}(T)=A_{\|} \exp \left[-\frac{E_{\|}}{k_{\mathrm{B}} T}\right] / I_{0}^{2}\left[\frac{V}{2 k_{\mathrm{B}} T}\right]
$$

where $I_{0}$ is the modified Bessel function of first kind of order 0 .

We have compared this model to the data as follows. We have assumed that this model is the correct one for the smectic A phase and determined the four parameters $A_{\perp}, E_{\perp}, A_{\|}, E_{\|}$, first by fitting Eq. (3) to the data giving $D_{\perp}$ in the smectic A phase (Fig. 6 of ref. [3]), then by fitting Eq. (5) to the data giving $D_{\|}$in the smectic A phase also (same figure). In this last operation, the value of $V$ was fixed to $1.1 \mathrm{kcal} / \mathrm{mol}$ which corresponds to the most probable value estimated from neutron data at intermediate $Q$ values [8]. The result of the fits is

$$
\begin{gathered}
A_{\perp}=0.12 \mathrm{~cm}^{2} / \mathrm{s}, \quad E_{\perp}=9.7 \mathrm{kcal} / \mathrm{mol}, \\
A_{\|}=7.5 \times 10^{3} \mathrm{~cm}^{2} / \mathrm{s}, \quad E_{\perp}=17.5 \mathrm{kcal} / \mathrm{mol} .
\end{gathered}
$$

Assuming these values of the parameters we have then calculated $D_{\perp}$ and $D_{\|}$in the nematic phase using Eqs. (3) and (4) respectively, and finally calculated $\bar{D}$ using Eq. (2). The result is shown in broken line in figure 2. It is seen that this model explains satisfactorily the neutron results. In particular, it explains the small discontinuity of $\bar{D}$ observed at the smectic A-nematic transition. On the contrary, it cannot explain the NMR data in the nematic phase [6], in particular the jump in $D_{\perp}$ at the smectic Anematic transition. For $D_{\|}$, a value of $V$ larger than $3 \mathrm{kcal} / \mathrm{mol}$ would be needed to explain a jump by a factor of $\sim 4$ at the same transition. Such a large value of $V$ is excluded by the results of ref. [8]. This was in fact the main reason which motivated the present neutron measurements.

5. Conclusion. - In summary, we have shown that the values of the diffusion coefficients of nematic TBBA measured by the NMR method using the nematic echo [6] are probably not correct. It is not clear for us if this situation is specific for TBBA or if the method itself should be questioned. In any case, the problem deserves an explanation from the NMR specialists. In conclusion, it appears that the neutron method using the back-scattering technique, if correctly used (sufficiently low $Q$ values), is a reliable spectroscopic means to measure self diffusion coefficients in liquid crystals. However, the experimental difficulties (preparation of large monodomains, long counting time) makes that it cannot be a routine method, and that the NMR methods are certainly more practical. The magic angle method [3] can be used for smectics. The multipulse method of ref. [4], which has also been used previously for nematics [9], should be modified according to the prescriptions of ref. [5] to give reliable results. We indeed learned [10] that this modified version now yields correct results for both smectics and nematics.

We are indebted to Professor P. G. de Gennes for fruitful discussions. 


\section{References}

[1] Dianoux, A. J., Volino, F., Heidemann, A. and Hervet, H., J. Physique Lett. 36 (1975) L-275.

[2] Dianoux, A. J., Heidemann, A., Volino, F. and Hervet, H., Molec. Phys. 35 (1976) 1521.

[3] KRÜGER, G. J., SPIESECKe, H., VAN STEENwINKel, R., J. Physique Colloq. 37 (1976) C3-123.

[4] Blinc, R., Burgar, M., Luzar, M., Pirš, J., Zupančič, I. and Žumer, S., Phys. Rev. Lett. 33 (1974) 1192

[5] Stepišnik, J., Proc. 3rd European Experimental NMR Conf. Elsinore (April 1977).
[6] Krüger, G. J. and Weiss, R., J. Physique 38 (1977) 353.

[7] Krüger, G. J., SpIesecke, H., Van Steenwinkel, R. and NoACK, F., Mol. Cryst. Liq. Cryst. 40 (1977) 103.

[8] Volino, F. and Dianoux, A. J., Molec. Phys. 36 (1978) 389.

[9] Zupančıč, I., Pirš, J., LuZar, M., Blinc, R. and Doane, J. W., Solid State Commun. 15 (1974) 227.

[10] Blinc, R., Private communication. 